\title{
METABOLIZAÇÃO DE MONOSSACARÍDEOS DA BIOMASSA VEGETAL POR LEVEDURAS ISOLADAS DE LARANJAS EM DECOMPOSIÇÃO.
}

\author{
L. R. ADORNO ${ }^{1, *}$, , Y. C. MIGNONI ${ }^{1, \#}$, E. T. BARRILLI ${ }^{1}$, S. P. TIRONI ${ }^{2}$, \\ S. L. ALVES JR. ${ }^{1}$ \\ ${ }^{1}$ Engenharia Ambiental e Sanitária, Campus Chapecó, Universidade Federal da Fronteira Sul \\ ${ }^{2}$ Agronomia, Campus Chapecó, Universidade Federal da Fronteira Sul \\ *E-mail para contato: lucy.rodriguesadorno@gmail.com \\ \#Ambos autores contribuíram igualmente para este trabalho
}

\begin{abstract}
RESUMO - O Brasil é o segundo maior produtor mundial de etanol, porém sua produção é quase que exclusivamente proveniente da fermentação de sacarose, contida no caldo de cana-de-açúcar, pela levedura Saccharomyces cerevisiae. É ainda possível aumentar a produção de etanol se forem viabilizadas fermentações a partir de diferentes fontes de biomassa vegetal, como cascas e bagaços de frutas. Entretanto, grande parcela dos carboidratos presentes nessas fontes não pode ser fermentada por S. cerevisiae. Nesse sentido, e considerando o expressivo volume da produção de laranjas no país, objetivou-se o isolamento de leveduras de amostras de casca e bagaço dessa fruta em decomposição e a caracterização bioquímica desses microrganismos. Dentre as cepas isoladas, três foram escolhidas e cultivadas em meios contendo glicose, frutose, xilose ou galactose como fontes de carbono. A partir de alíquotas dessas culturas foi possível a determinação dos perfis de crescimento celular, consumo de açúcares e produção de etanol. As análises demostraram que, embora as cepas analisadas tenham apresentado dificuldade em consumir a galactose, elas iniciaram o consumo dos outros monossacarídeos entre 10 e 20 h de incubação. Duas delas apresentaram rendimento de etanol a partir da xilose igual ou superior ao obtido com a glicose. Assim, os dados indicam ser possível encontrar leveduras selvagens capazes de contribuir com a otimização da produção de etanol a partir de diferentes fontes de biomassa vegetal.
\end{abstract}

\section{INTRODUÇÃO}

No Brasil, o etanol de primeira geração produzido a partir da fermentação do caldo de cana-de-açúcar surgiu no início dos anos 70 como tentativa atenuante das seguidas crises de petróleo que atingiam o país. Atualmente, o Brasil é o segundo maior produtor de álcool combustível no mundo, com uma produção de aproximadamente 27 bilhões de litros. Como consequência dessa produção, aproximadamente 150 milhões de toneladas de resíduos como bagaço e palha da cana-de-açúcar são gerados anualmente no país (Silva et al., 2014). Da mesma forma que o bagaço e palha de cana podem ser utilizados para a produção de etanol de segunda geração - oriunda da fermentação de materiais lignocelulósicos — outras fontes de biomassas também podem ser empregadas. Segundo o Departamento de Agricultura dos Estados Unidos (USDA) (2016), a produção de sucos cítricos processa anualmente cerca de $45,8 \cdot 10^{6}$ toneladas de frutas ao redor do mundo. 
De acordo com Siles Lopez et al. (2010), a extração do suco de laranja gera o equivalente a $50 \%$ do peso da fruta em rejeito, subproduto que, atualmente, tem sido empregado para alimentação de animais e, como apresentado por Edwards e Doran-Peterson (2012), não possui retorno econômico significativo. Segundo Rivas et al. (2008), a biomassa da laranja compõe-se basicamente de celulose, hemicelulose, açúcares solúveis e pectina. Sabe-se, por outro lado, que significativa parcela dos carboidratos presentes nessas matériasprimas não pode ser fermentada pela levedura S. cerevisiae e, sendo assim, encontrar uma levedura capaz de realizar sua fermentação é importante para aumentar a viabilidade da produção do etanol de segunda geração (Van Maris et al., 2006). Neste contexto, o presente trabalho teve como objetivo analisar leveduras isoladas de laranjas em decomposição em meios contendo diferentes fontes de carbono, haja vista a possibilidade de abrir um novo mercado economicamente rentável para os resíduos da indústria de sucos cítricos.

\section{MATERIAIS E MÉTODOS}

\subsection{Isolamentos de Leveduras e Linhagens Utilizadas}

As leveduras analisadas foram isoladas a partir de amostras de laranjas em decomposição coletadas no oeste de Santa Catarina. As amostras foram recebidas em sacos estéreis termicamente isolados e identificados como sugere o protocolo descrito por Cadete et al. (2009). Retirou-se, aleatoriamente, um grama das amostras para serem inoculadas em frascos Erlenmeyer com $25 \mathrm{~mL}$ de meio líquido, composto por $0,67 \%$ de base nitrogenada, $0,02 \%$ de cloranfenicol e $1 \%$ de xilose. Os frascos foram incubados a uma temperatura de $28^{\circ} \mathrm{C}$ sob agitação constante de $145 \mathrm{rpm}$ e, quando detectado crescimento celular através da turbidez dos meios, uma alçada de células de cada amostra foi retirada para a realização do esgotamento por estriamento. As placas de Petri utilizadas no esgotamento continham os mesmos meios supracitados além da adição de $2 \%$ de ágar, e foram incubadas a $25^{\circ} \mathrm{C}$. Posteriormente selecionaram-se as leveduras com base na morfologia de colônia. As linhagens foram identificadas, individualmente, a partir da sigla CHAP sucedidos por um número variante entre 45 e 82, seguindo a numeração da coleção do grupo de pesquisa.

\subsection{Crescimentos Celulares, Consumo de Açúcares e Produção de Etanol}

Para realização dos crescimentos celulares escolheu-se, aleatoriamente, três linhagens dentre as isoladas: CHAP-047, CHAP-070 e CHAP-078. Além dessas, analisou-se também o crescimento da linhagem industrial CAT-1, da espécie $S$. cerevisiae, identificada por Basso et al. (2008). As leveduras foram pré-cultivadas em frascos Erlenmeyer por $48 \mathrm{~h}$ contendo 10 $\mathrm{mL}$ de meio rico ( $1 \%$ de extrato de levedura, $2 \%$ de peptona e $2 \%$ de glicose). O inóculo (1/100 do volume final) foi transferido a Erlenmeyers com meios mínimos compostos por $0,67 \%$ de base nitrogenada e $2 \%$ de glicose, frutose, xilose ou galactose, como fontes de carbono; e pH ajustado em 5,0. As culturas foram incubadas sob agitação constante de 145 $\mathrm{rpm}$ e $25^{\circ} \mathrm{C}$, onde, ao decorrer do crescimento, em intervalos pré-estabelecidos, foram retiradas amostras, totalizando um período de amostragem de 48 horas. A partir dessas amostras realizaram-se as determinações do crescimento celular através da medição da densidade óptica $\left(\mathrm{DO}_{570}\right)$ utilizando um espectrofotômetro. No mesmo intervalo de tempo pré-estabelecido, retirou-se uma alíquota de cada meio, submetendo-a a centrifugação. $\mathrm{O}$ 
sobrenadante foi coletado e congelado para uma posterior dosagem de etanol e determinação do consumo de açúcares.

A determinação do consumo de carboidratos durante os crescimentos celulares foi realizada através do método de DNS em microplacas descrito por Santos et al. (2017). O etanol produzido pelas cepas durante os crescimentos celulares foi quantificado enzimaticamente seguindo adaptações realizadas na metodologia descrita por Rodionov et al. (2002). Para essa determinação $10,0 \mu \mathrm{L}$ de amostra foram incubados em microplacas de 96 poços (de fundo plano) com $200,0 \mu \mathrm{L}$ do reagente enzimático, pelo período de 2 horas, à temperatura de $37^{\circ} \mathrm{C}$. Após incubação, a absorbância foi medida através de leitor de microplacas, com feixe de luz a $490 \mathrm{~nm}$. A concentração de etanol foi determinada através da correlação do valor de absorbância apresentada para cada amostra, com a equação de reta extraída da curva de calibração, retiradas diretamente em planilhas do Microsoft ${ }^{\circledR}$ Excel. Os rendimentos de etanol foram calculados conforme Schmidell et al. (2001), correlacionando o produto obtido com o substrato consumido $\left(Y_{e / s}\right)$.

\section{RESULTADOS E DISCUSSÕES}

$\mathrm{Na}$ etapa de isolamento das leveduras de laranjas em decomposição, obteve-se 38 linhagens. Dentre essas, três foram aleatoriamente escolhidas para análise dos perfis de crescimento celular, consumo de açúcares e produção de etanol: CHAP-047, CHAP-070 e CHAP-078. Todas as linhagens foram capazes de crescer em meios contendo alternadamente glicose, frutose ou xilose como fontes de carbono. O início das suas fases exponenciais de crescimento nos meios com esses carboidratos oscilou entre 10 e 20 horas após a inoculação, tendo a CHAP-047 apresentado a menor fase lag (Figura 1). Essas leveduras, entretanto, tiveram dificuldade em consumir a galactose. A assimilação dessa hexose só iniciou após $35 \mathrm{~h}$ de cultivo, e as células não foram capazes de consumir por completo os $20 \mathrm{~g} / \mathrm{L}$ disponíveis durante as $48 \mathrm{~h}$ de incubação (Figura 1B, 1D e 1F).

Os quatro monossacarídeos testados estão entre os principais constituintes do bagaço e da casca de frutas (Huang et al., 2014). Contudo, a literatura tem apontado que a pentose xilose, o segundo açúcar mais abundante nessa biomassa, não pode ser fermentada por $S$. cerevisiae (Stambuk et al., 2008). De fato, ao testarmos a cepa industrial CAT-1, da espécie $S$. cerevisiae, em meios com as mesmas fontes de carbono utilizadas com as linhagens isoladas de laranjas, pôde-se verificar que as células, embora tenham crescido em glicose e frutose rapidamente, não foram capazes de se reproduzir em xilose (Figura 2). Por outro lado, o crescimento da CAT-1 em galactose foi mais expressivo do que o observado para as três leveduras selvagens aqui testadas.

Em contrapartida, as linhagens CHAP-047 e CHAP-078 não apenas foram capazes de consumir a xilose como foram capazes de fermentá-la, produzindo, respectivamente, 1,81 e $2,87 \mathrm{~g} / \mathrm{L}$ de etanol a partir do que lhes foi disponibilizado dessa pentose no meio de cultura. $\mathrm{O}$ rendimento de etanol $\left(Y_{e / s}\right)$ dessas leveduras está apresentado na Figura 3. Percebe-se que ambas apresentaram rendimento em xilose igual ou maior do que o observado em glicose - a linhagem CHAP-047, embora não tenha apresentado a mesma performance da CHAP-078, teve rendimento de etanol a partir da xilose duas vezes superior ao observado a partir da fermentação da glicose. 
Figura 1 - Perfis de crescimento celular (A, C e E) e consumo de açúcares (B, D e F) das linhagens CHAP-047 (A, B), CHAP-070 (C, D) e CHAP-078 (E, F) em meios contendo glicose $(\square)$, frutose $(\Delta)$, xilose $(\bullet)$ ou galactose $(ж)$ como fonte de carbono.

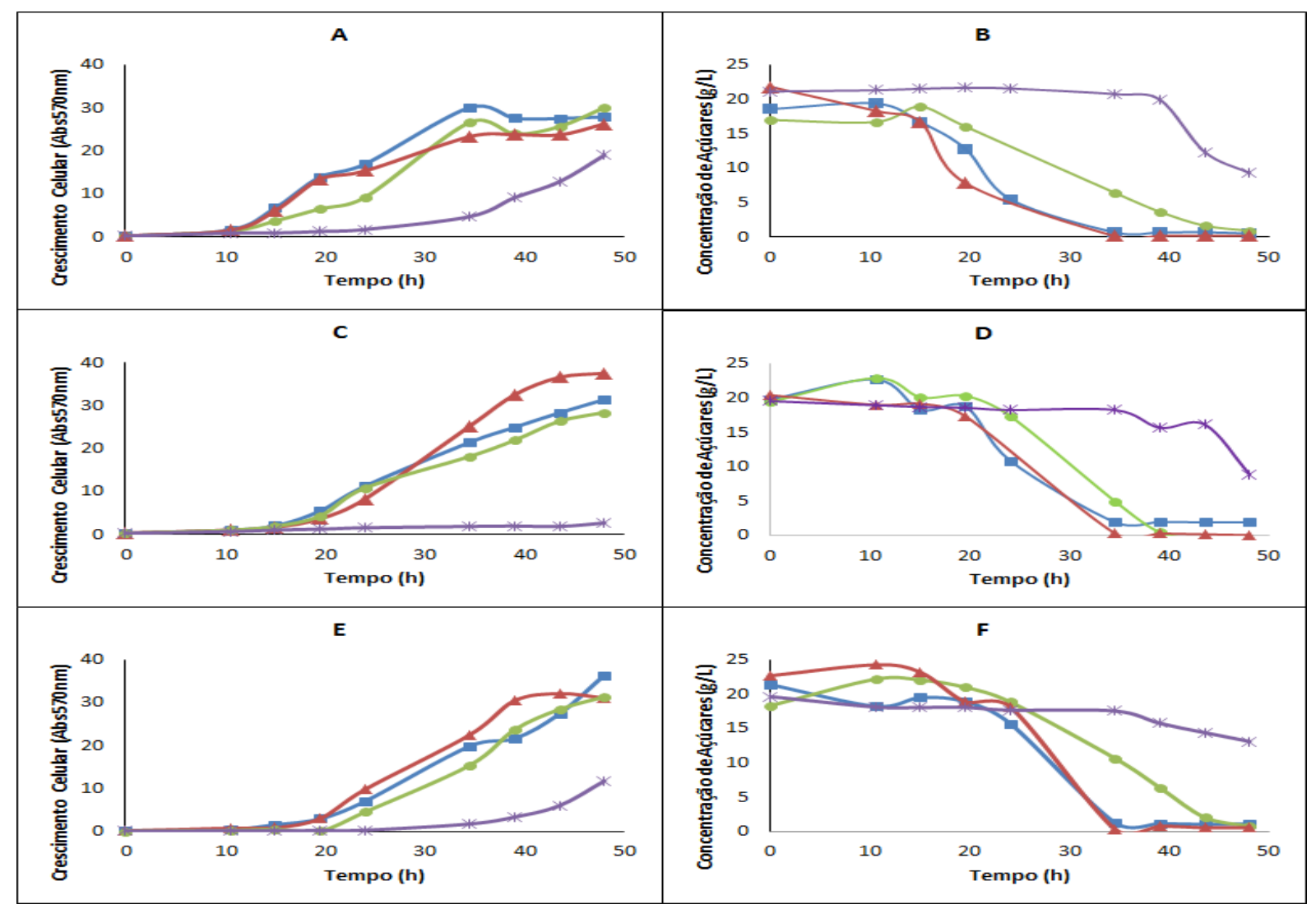

Figura 2 - Crescimento celular da linhagem CAT-1 de S. cerevisiae em meios contendo glicose $(\square)$, frutose $(\triangle)$, xilose $(\bullet)$ ou galactose $(ж)$ como fonte de carbono.

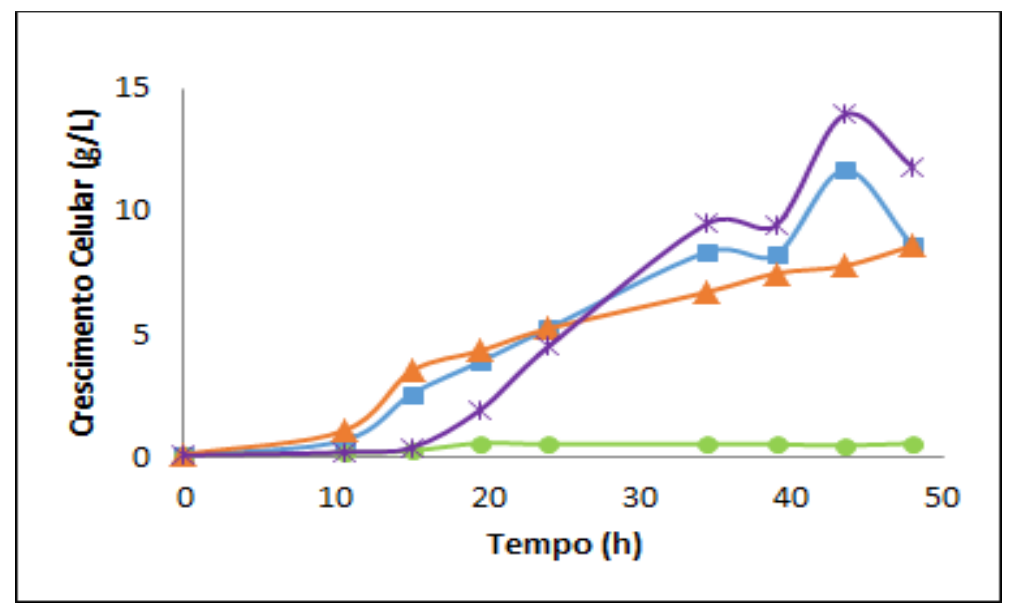


Figura 3 - Rendimento de etanol (em g/g) das leveduras isoladas de laranja em decomposição.

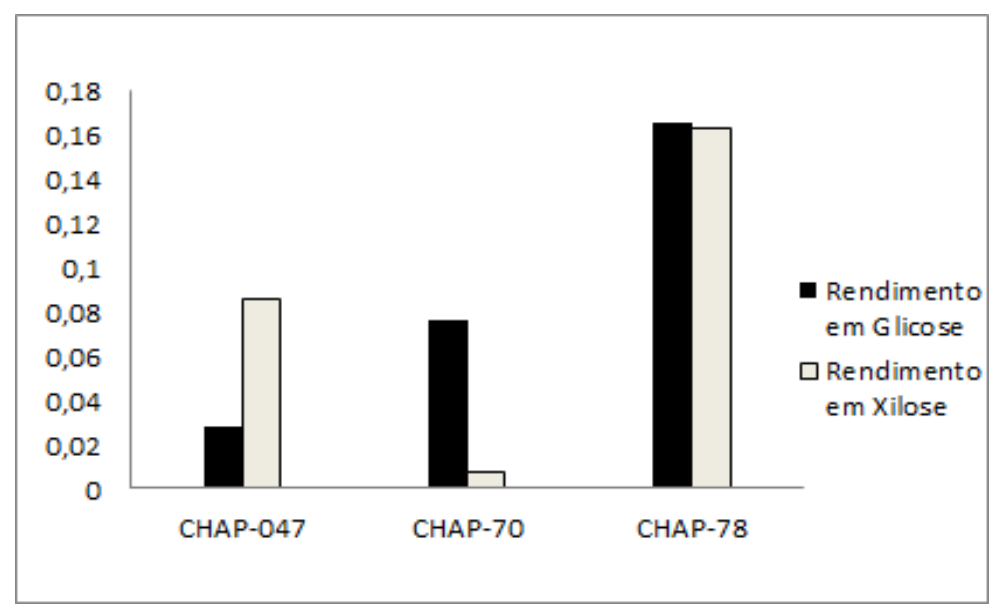

Hande et al. (2013) demonstraram que a fonte de nitrogênio é importante para o rendimento fermentativo das leveduras. Em seu trabalho, esses autores apontam que o rendimento de etanol em meios contendo amônia como fonte de nitrogênio (como foram os meios utilizados no presente trabalho) é apenas pouco mais da metade do rendimento observado em meios cuja fonte de nitrogênio provenha de extrato de levedura e peptona. Levando em conta os dados daqueles autores, e considerando ser de 0,51 g/g o rendimento teórico máximo de etanol, é possível inferir que as leveduras selvagens aqui testadas têm potencial para contribuir com a viabilização da produção de etanol de segunda geração. Novos trabalhos poderiam avaliar o rendimento fermentativo dessas leveduras em meios com diferentes fontes de nitrogênio.

\section{CONCLUSÃO}

Os dados obtidos sugerem ser possível encontrar leveduras selvagens capazes de fermentar açúcares não metabolizados por $S$. cerevisiae e, portanto, de contribuir com a otimização da produção de etanol a partir de diferentes fontes de biomassa vegetal residual. Ademais, entre os isolados testados, a cepa CHAP-078 se destacou quanto ao rendimento de etanol a partir da xilose disponibilizada em meio sintético mínimo, indicando ter ela potencial para aplicação industrial. Novos trabalhos, entretanto, poderão verificar a capacidade dessa levedura de suportar as condições de estresse das dornas de fermentação.

\section{REFERÊNCIAS}

BASSO, L.C.; AMORIM, H.V.; DE OLIVEIRA, A.J.; LOPES, M. L. Yeast selection for fuel ethanol production in Brazil. FEMS Yeast Res., v. 8: p. 1155-1163, 2008.

CADETE, R. M.; SANTOS, R. O.; MELO, M. A.; MOURO, A.; GONÇALVES, D. L.; STAMBUK, B. U.; GOMES, F. C. O.; LACHANCE, M. A.; ROSA, C. A. Spathaspora arborariae sp. nov., a D-xylose-fermenting yeast species isolated from rotting wood in Brazil. FEMS Yeast Res., v. 9, p. 1338-1342, 2009. 
EDWARDS, M. C.; PETERSON, J. D. Pectin-rich biomass as feedstock for fuel ethanol production. Appl. Microbiol. Biotechnol., v. 95, p. 565-575, 2012.

HANDE, A.; MAHAJAN, S.; PRABHUNE, A. Evaluation of ethanol production by a new isolate of yeast during fermentation in synthetic medium and sugarcane bagasse hemicellulosic hydrolysate. Ann. Microbiol., v. 63, p 63-70, 2013.

HUANG, R.; CAO, M.; GUO, H.; QI, W.; SU, R.; HE, Z. Enhanced ethanol production from pomelo peel waste by integrated hydrothermal treatment, multienzyme formulation, and fed-batch operation. J. Agric. Food Chem., v. 62, p. 4643-4651, 2014.

RIVAS, B.; TORRADO, A.; TORRES, P.; CONVERTI, A.; DOMINGUÉX, J.M. Submerged Citric Acid Fermentation on Orange Peel Autohydrolysate, J. Agric. Food Chem., v. 56, p. 2380-2387, 2008.

RODIONOV, Y. V.; KEPPEN, O. I.; SUKHACHEVA, M. V. A photometric assay for ethanol. Appl. Biochem. Microbiol., v. 38, p. 395-396, 2002.

SANTOS, A. A.; DEOTI, J. R.; MÜLLER, G.; DÁRIO, M. G.; STAMBUK, B. U.; ALVES, S. L. Jr. Microwell plate-based method for the determination of reducing sugars with the DNS reagent. Braz. J. Food Technol., v. 20, p. e2015113, 2017.

SCHMIDELL, W.; LIMA, U. D. A.; AQUARONE, E.; BORZANI, W. Modelagem matemática e simulação de processos fermentativos. Biotechnol. Ind., v. 2, p. 123-178, 2001.

SILES LOPEZ, J. A.; LI, Q.; THOMPSON, I. P. Biorefinery of waste orange peel. Crit. Rev. Biotechnol., v. 30, p. 63-69, 2010.

SILVA, L. F.; TACIRO, M. K.; RAICHER, G.; PICOLLI, R. A.; MENDONÇA, T. T.; LOPES, M. S.; GOMEZ, J. G. Perspectives on the production of polyhydroxyalkanoates in biorefineries associated with the production of sugar and ethanol. Int. J. Biol. Macromol., v. 71, p. 2-7, 2014.

STAMBUK, B. U.; ELEUTHERIO, E. A.; FLOREZ-PARDO, L. M.; SOUTO-MAIOR, A.; BON, E. S. Brazilian potential for biomass ethanol: challenge of using hexose and pentose cofermenting yeast strains. J. Sci. Ind. Res., v. 67, p. 918-926, 2008.

USDA. UNITED STATES DEPARTMENT OF AGRICULTURE. Citrus: World markets and Trade (2016).

VAN MARIS, A. J. A; ABBOTT, D.A.; BELLISSIMI, E.; VAN DEN BRINK, J.; KUYPER, M.; LUTTIK, M. A. H.; WISSELINK, H. W.; SCHEFFERS, W.A.; VAN DIJKEN, J.P.; PRONK, J. T. Alcoholic fermentation of carbon sources in biomass hydrolysates by Saccharomyces cereviesiae: current status. Antonie van Leeuwenhock, v. 90, p. 391418, 2006. 